\title{
$\gamma$-Tocopherol as a possible marker for nutrition-related risk: results from four National Diet and Nutrition Surveys in Britain
}

\author{
C. J. Bates*, G. D. Mishra and A. Prentice \\ MRC Human Nutrition Research, Elsie Widdowson Laboratory, Fulbourn Road, Cambridge CB1 9NL, UK \\ (Received 3 September 2003 - Revised 19 February 2004 - Accepted 29 February 2004)
}

\begin{abstract}
Relationships between vitamin E status ( $\alpha$ and $\gamma$-tocopherol and their ratio in plasma), anthropometric and biochemical indices, and food and nutrient intakes, were studied in four British National Diet and Nutrition Surveys: children aged 1.5-4.5 years, young people aged 4.0-18.0 years, adults 19.0-64.0 years and adults aged $\geq 65.0$ years. $\gamma$-Tocopherol: $\alpha$-tocopherol ratio declined with age. In older women $\gamma$-tocopherol and $\gamma$-tocopherol: $\alpha$-tocopherol ratios were directly related to indices of obesity. In young men $\alpha$ - and $\gamma$-tocopherols were directly correlated with obesity, but $\gamma$-tocopherol: $\alpha$-tocopherol ratio was not. For young people and toddlers, fewer obesity indices were available and relationships were weaker. Other fat- and water-soluble vitamin indices correlated directly with $\alpha$-tocopherol and inversely with $\gamma$-tocopherol and $\gamma$-tocopherol: $\alpha$-tocopherol ratio. Whereas $\alpha$-tocopherol correlated directly with 'healthy' nutrient choices (such as intrinsic sugars, dietary fibre, vitamins and potassium) and inversely with 'unhealthy' choices (extrinsic sugars and monounsaturated fats, i.e. avoidance of polyunsaturated fat), $\gamma$-tocopherol and the $\gamma$-tocopherol: $\alpha$-tocopherol ratio related inversely with 'healthy' choices. Food groups had analogous relationships; thus, $\alpha$-tocopherol related directly to use of polyunsaturated fats, fresh fruits and fruit juices, and inversely to non-polyunsaturated fats and extrinsic sugar. The reverse was true for $\gamma$-tocopherol and $\gamma$-tocopherol: $\alpha$-tocopherol ratio. Although the mechanisms underlying these relationships are obscure, the $\gamma$-tocopherol: $\alpha$-tocopherol ratio may reveal poor dietary choices, status predictors and a propensity for obesity in later life, especially in women.
\end{abstract}

$\gamma$-Tocopherol: Britain: Survey: Risk indices: Anthropometry: Nutrient intakes: Biochemical markers

Textbook descriptions of the biological significance of the different forms of vitamin $\mathrm{E}$ in the diet usually ascribe dominant significance to $\alpha$-tocopherol, particularly to the $R R R$-form, which is retained in greater amounts and for longer than the other forms of tocopherol; this is mainly because of its preferential affinity for $\alpha$-tocopherol transfer protein, which protects it from degradation (Blatt et al. 2001). $\gamma$-Tocopherol, which is the major component of vitamin $\mathrm{E}$ in some plant oils such as soyabean oil (McLaughlin \& Weihrauch, 1979) and is quantitatively the largest vitamin E component in some modern human diets (Jiang et al. 2001; White et al. 2001; Dietrich et al. 2003 ), is more readily oxidised and/or eliminated than $\alpha$ tocopherol (Traber \& Kayden, 1989; Swanson et al. 1999; Blatt et al. 2001; Sontag \& Parker, 2002) and is usually only a minor component of the vitamin $\mathrm{E}$ in blood plasma, where vitamin $\mathrm{E}$ status is commonly measured.

However, some recent studies have challenged the assumption that because $\gamma$-tocopherol is degraded more quickly, it is of only minor biological significance. One property that it does not share with $\alpha$-tocopherol is its rapid conversion in vivo to a more polar chroman, 2,7,8-trimethyl-2-(2'-carboxyethyl)-6-hydroxychroman, which has diuretic and natriuretic properties (Wechter et al. 1996). Some recent studies have indicated that $\gamma$-tocopherol may possess protective properties that are not shared by $\alpha$-tocopherol (Jiang et al. 2001), whereas others have proposed that its unique properties may increase the risk of tissue damage and disease (Cornwell et al. 2002). Although there is disagreement about the health significance of $\gamma$-tocopherol (Ohrvall et al. 1996; Kontush et al. 1999; Jiang et al. 2001; Lemcke-Norojarvi et al. 2001; Cornwell et al. 2002; Devaraj \& Traber, 2003), there is a growing realisation that it possesses metabolic attributes that are not shared by the $\alpha$-isomer, and that it may therefore be differently related to risk indices and factors. One recent and intriguing study (White et al. 2001) reported that amongst postmenopausal women in the USA, higher plasma $\gamma$-tocopherol concentrations were associated with higher BMI and with lower serum concentrations of retinol, carotenoids, less use of supplements of vitamins $\mathrm{C}$ and $\mathrm{E}$, lower $\alpha$-tocopherol intake and less dietary fibre from food. It suggested that plasma concentrations of $\alpha$ and $\gamma$-tocopherol may change in opposite directions in response to different dietary choices and risk indices, and may thus possess fundamentally different predictive properties. The association of $\gamma$-tocopherol with increased 
risk (e.g. risk of obesity, less healthy dietary choices and less favourable blood status indices) seems paradoxically at odds with the common perception that a vitamin E-rich diet is usually associated with healthy dietary choices and a lowering of risk of CVD.

An opportunity to confirm and extend these observations in a different setting, and in a contrasting western population, where the use of dietary supplements is less widespread than it is in the USA, was provided by the National Diet and Nutrition Survey (NDNS) series: this was carried out in Britain during the final 10 years of the 20th century. This NDNS series, designed so as to be representative of the British population, has provided an opportunity to study men and women in several age groups and to explore the predictive properties of $\gamma$-tocopherol in several different segments of the British population.

\section{Subjects and methods}

The NDNS series was commissioned by the Department of Health and by the Ministry of Agriculture, Fisheries and Food, whose responsibility has recently passed to the Food Standards Agency. The survey design, methodologies and principal results have been published in a series of reports that are available from The Stationery Office (London, UK). The surveys were each approved by the appropriate local research ethics committees in each of the postcode areas in which the fieldwork was performed.

Briefly, the generic design can be summarised as follows. Four separate surveys of mainland Britain addressed the four age-bands: $1.5-4.5,4-18,19-64$ and $\geq 65$ years. The present study addresses all four surveys, q.v. the published survey reports (Gregory et al. 1995, 2000; Finch et al. 1998; Henderson et al. 2003a,b; Ruston et al. 2004). The survey of people aged $\geq 65$ years (Finch et al. 1998) comprised two populations: those living in the community ('free-living'), and those living in institutions, such as nursing homes. Since the survey methodologies were slightly different between these two populations, the present study has made use of the results from the free-living group only, which was the larger of the two groups and was the more closely analogous to the populations of younger people in the community, who were studied in the other three surveys. Since the relationships between the anthropometric and biochemical indices were found to change with age, the results of the surveys on adults were subdivided into those for young adults aged 19-34 years and those for middle-aged adults aged 35-64 years.

Subjects who were regularly taking vitamin E supplements (recorded during the 4 or $7 \mathrm{~d}$ weighed dietary intake record that was used as the diet assessment instrument in the surveys; see survey reports for further details) were excluded from all of the analyses in the present paper.

Subject selection was by random selection of postcode sectors followed by random stratified selection (by age subgroup and gender) of all eligible members of the population. Fieldwork was spread over one calendar year so as to include all four seasons. Between 2000 and 2500 subjects were recruited as a representative sample of the British population in the chosen age group in each survey. About two-thirds of these respondents provided a weighed dietary record for four or for seven consecutive days, depending on the age group. For surveys on toddlers and $\geq 65$-year-olds it was $4 \mathrm{~d}$, whereas for the adults and 4-18-year-olds it was a $7 \mathrm{~d}$ estimate. This, and other socio-demographic and lifestyle information was provided either by the subject themselves, or by parents or guardians (of young children) or by carers (of older people with mental frailty). About half of the participants in each age group provided a blood sample during the same time period as the diet assessment, which was analysed for a wide range of indices, including vitamin, mineral and clinical chemistry markers. For the surveys on toddlers and adults it was a non-fasting sample, whereas for the 4-18- and $\geq 65$-year-olds the blood sample was taken after an overnight fast.

Anthropometric measurements were obtained for most of the subjects who provided the other key (dietary and biochemical) information. The choice of these measurements varied between surveys, but they regularly included body weight, height (or length) and hence BMI. For adults, measurements of waist and hip circumference were also included. The 4 or $7 \mathrm{~d}$ weighed food intake records were converted to: (1) a summary of food choices based on food-group allocation of items consumed, expressed on a weekly basis; (2) daily nutrient intakes, derived from food-nutrient content tables developed by the Ministry of Agriculture Fisheries and Food and the Food Standards Agency.

The biochemical index measurement techniques are described in appendices to the survey reports. Only the assay for plasma fat-soluble vitamins $\mathrm{A}$ and $\mathrm{E}$ and plasma carotenoids is described here, since this assay is central to the topic of the present study. From heparinanticoagulated blood, the separated plasma was stored frozen at $-85^{\circ} \mathrm{C}$, and the fat-soluble vitamins and carotenoids were analysed by HPLC with optical density detection.

The fat-soluble vitamins (including tocopherols and carotenoids) assay procedure was derived from that of Thurnham et al. (1988) and was carried out in the same laboratory for all four surveys. Samples of plasma (typically $250 \mu \mathrm{l}$ ) were extracted with $n$-heptane in the presence of absolute ethanol, butylated hydroxytoluene and internal standard mixture (see later). The upper organic phase was evaporated nearly to dryness under vacuum, and was then dissolved in $250 \mu \mathrm{l}$ of the HPLC mobile phase. If necessary, a small volume of dichloromethane was added first, to achieve complete dissolution. Aliquots of $50 \mu \mathrm{l}$ were then injected onto a $4 \mu \mathrm{m}$ Waters $\mathrm{C}_{18}$ column (Waters, Milford, MA, USA), which was preceded by a $0.5 \mu$ reduced stainless-steel filter frit, to remove any contaminating particles. The HPLC mobile phase comprised (ml/l): acetonitrile 440, methanol 440, dichloromethane 120 , with added butylated hydroxytoluene $(10 \mathrm{mg} / \mathrm{l})$. The flow rate was $1.5 \mathrm{ml} / \mathrm{min}$ and the column temperature control jacket was maintained at $25^{\circ} \mathrm{C}$. We used a Waters Millennium-controlled HPLC system, with a multi-wavelength optical density detector. An internal standard, either tocopheryl acetate alone or a triple standard, containing retinyl acetate, tocopheryl acetate and ethyl $\beta$-apo- $\delta^{\prime}$-carotenoate, was added to monitor the plasma component recoveries. 
Retinol and retinyl palmitate were estimated by optical density at $325 \mathrm{~nm}$, and tocopherols at $292 \mathrm{~nm}$, at which wavelength the tocopheryl acetate standard was also measured. Carotenoids were measured at $450 \mathrm{~nm}$. Peak area response factors were obtained from semi-pure, commercially available carotenoids, and from retinol, retinyl palmitate, $\alpha$-tocopherol and $\gamma$-tocopherol. These were then corrected to $100 \%$ purity by means of their HPLC patterns and from their absolute optical densities and known extinction coefficients. Run time was 13 min. Quality control procedures included: (1) subdivided human plasma sample for long-term drift control; (2) freezedried 'quality control' plasma, including SRM 968c FatSoluble Vitamins, Carotenoids and Cholesterol in Human Serum, provided by the National Institute of Standards and Technology (Gaithersburg, MD, USA), and participation in the regular National Institute of Standards and Technology 'round-robin' exchange scheme. Plasma cholesterol was measured by standard techniques in all four surveys. In the two surveys where the blood samples were collected after an overnight fast (i.e. the surveys for $\geq 65$ - and the 4-18-year-olds), plasma total triacylglycerol was also measured by standard techniques (see survey report appendices).

\section{Outcome measures}

The indicators of obesity used in the present study were high BMI ( $\geq 25 \mathrm{~kg} / \mathrm{m}^{2}$ in men and in women), high waist circumference (see later) and high waist:hip ratio $(\geq 0.95$ in men and $\geq 0.80$ in women). Large waist circumference, indicative of increased CVD risk, was defined at two action levels: action level 1, exceeding $0.94 \mathrm{~m}$ in men and $0.80 \mathrm{~m}$ in women; action level 2, exceeding $1.02 \mathrm{~m}$ in men and $0.88 \mathrm{~m}$ in women (Han et al. 1995). To determine if vitamin $\mathrm{E}$ indices were associated with a multiple number of indicators of obesity, a dummy variable was generated; this took a value of 1 if the subject had at least two of the three indicators of obesity (high BMI, waist circumference of at least $0.88 \mathrm{~m}$ in women and $0.94 \mathrm{~m}$ in men, high waist: hip ratio), and 0 otherwise.

Body weight, height and mid-upper-arm circumference were analysed as continuous variables.

\section{Statistical analysis}

As three of the indicators of obesity were considered as binary outcome variables, adjusted odds ratios and $95 \%$ CI were estimated for the risk of having each of the indicators of obesity separately, using multiple logistic regression with one of the three index of vitamin E status (i.e. the $\alpha$-tocopherol and $\gamma$-tocopherol concentrations and the $\gamma$-tocopherol: $\alpha$ tocopherol concentration ratios) as a covariate. Similarly, multiple linear regression analysis was performed separately with body weight, height and mid-upper-arm circumference considered as the outcome variables. The variable estimates in both the logistic regression and linear regression models were adjusted for the potentially confounding variables: plasma total cholesterol, and also where available, plasma triacylglycerol (see earlier). Most analyses were stratified by gender; the remainder were adjusted for gender and all were adjusted for age, both variables being entered as covariates in the multiple regression models. Logarithmic transformations of the $\alpha$-tocopherol and $\gamma$-tocopherol concentrations were performed before analysis to normalise their distributions. The food intake estimates (which included some zero values) were square-root transformed in order to reduce the skewness of their distributions. They, and the derived nutrient intakes (with the exception of food energy per se) were all adjusted for food energy by covariance. The analyses were performed using PROC LOGISTIC and PROC GLM in SAS (1999; SAS Insitute Inc., Cary, NC, USA).

\section{Results}

\section{Supplement users}

The proportion of subjects who were regularly taking vitamin E-containing dietary supplements, as indicated in their 4 or $7 \mathrm{~d}$ diet records, varied from $3-4 \%$ of toddlers and young people to $15-19 \%$ of adults and older adults. As noted earlier (p. 000), these subjects were excluded from all of the analyses described in the present paper.

\section{Age trends and relationships between vitamin E status indices}

Figure 1 shows the mean ratios of each of the two forms of vitamin E measured in plasma to plasma cholesterol, and the $\gamma$-tocopherol: $\alpha$-tocopherol ratio, by age subgroups of the four NDNS. In order to include all three vitamin E indices in the same figure it was necessary to multiply the $\gamma$ tocopherol:cholesterol ratios by 10 and the $\gamma$-tocopherol: $\alpha$ tocopherol ratios by 100 . An increase in concentration of plasma vitamin $\mathrm{E}$ per unit volume in older adults was accompanied by an increase in concentration of other plasma lipids such as cholesterol (results not shown).

The relationship of $\log _{e}$ (plasma $\gamma$-tocopherol) with $\log _{\mathrm{e}}$ (plasma $\alpha$-tocopherol) after adjustment for age, gender, plasma cholesterol, and for triacylglycerol where available, was determined in the four NDNS survey datasets. In all four surveys, the relationship was direct, i.e. positive, and was highly significant: $1.5-4 \cdot 5$-year-olds $t$ $+5 \cdot 5,624 \mathrm{df}, P<0.0001 ; 4-18$-year-olds $t+8 \cdot 2,924 \mathrm{df}$, $P<0 \cdot 0001 ; 19-64$-year-olds $t+10 \cdot 7,913 \mathrm{df}, P<0 \cdot 0001$; free-living $\geq 65$-year-olds $t+4 \cdot 2,704 \mathrm{df}, P<0 \cdot 0001$. In the following results section, the older subjects are described first, followed by the younger ones.

\section{Indicators of obesity in women aged $\geq 65$ years}

Of the older women, $65 \%$ had BMI of at least $25 \mathrm{~kg} / \mathrm{m}^{2}$ while $76 \%$ had a waist circumference of at least $0.80 \mathrm{~m}$. The waist:hip ratio was $>0.88$ in $46 \%$ and $39 \%$ had a combination of this plus high BMI and high waist:circumference. Table 1 shows, first, that among these older women, plasma $\gamma$-tocopherol concentration and the $\gamma$-tocopherol: $\alpha$-tocopherol ratio were positively associated with mid-upper-arm circumference. Second, women who had a higher waist circumference and a higher waist:hip ratio 


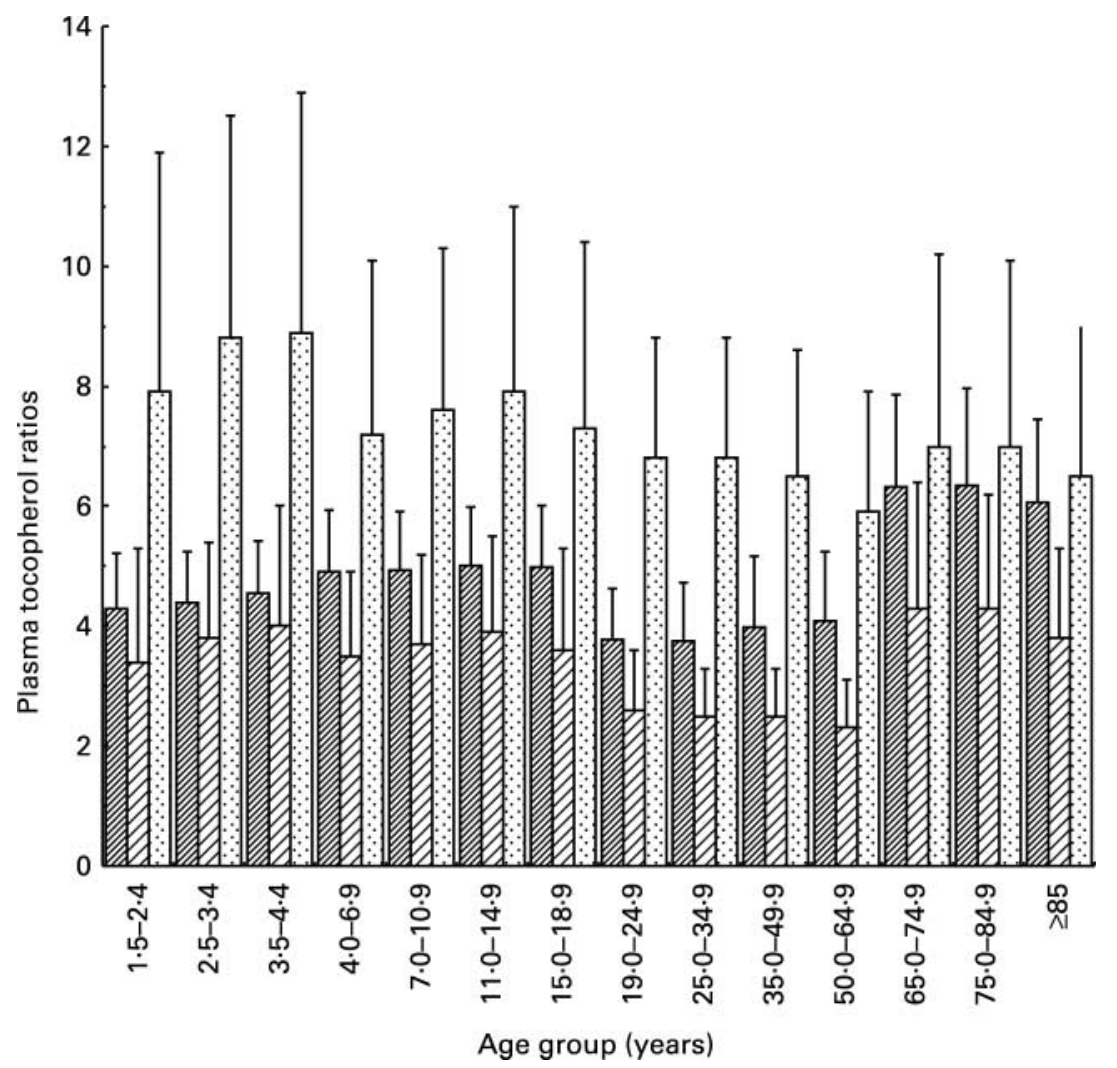

Fig. 1. Plasma tocopherol concentration ratios by age group. The $y$-axis shows the $\alpha$-tocopherol:cholesterol ratios $(\mathrm{mmol} / \mathrm{mol})$, the $\gamma$-tocopherol:cholesterol ratios $((\mathrm{mmol} / \mathrm{mol}) \times 10)$ and the $\gamma$-tocopherol: $\alpha$-tocopherol ratios $((\mathrm{mol} / \mathrm{mol}) \times 100)(\mathbb{Q}, \alpha$-tocopherol:cholesterol ratio; $\mathbb{}, \gamma$-toco-

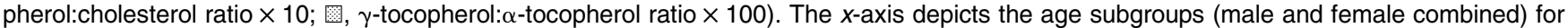
each National Diet and Nutrition Survey (NDNS) as follows: NDNS survey on 1.5-4.5-year-olds: 1.5-2.4, 2.5-3.4, 3.5-4.4 years old; NDNS survey on 4-18-year-olds: $4.0-6 \cdot 9,7 \cdot 0-10 \cdot 9,11 \cdot 0-14.9,15 \cdot 0-18.9$ years old; NDNS survey on 19-64-year-olds: 19.0-24.9, 25.0-34.9, $35.0-49.9,50 \cdot 0-64.9$ years old; NDNS survey on free-living $\geq 65$-year-olds: $65.0-74.9,75 \cdot 0-84.9, \geqq 85.0$ year olds. The three vitamin $\mathrm{E}$ index values for each age subgroup are depicted as arithmetic mean values with standard deviations shown by vertical bars. For the surveys on 4-18, 19-64 and $\geq 65$-years-olds, standardised weighting adjustments were used (q.v. the survey reports), to correct for imbalances between the groups in some of the socio-demographic characteristics of the respondents. These adjustments were entered, as a variance variable, so as to adjust the results in the figure. However, in no case did this result in more than a $2 \%$ change in the unadjusted values. No weighting adjustments were available for the survey on 1.5-4.5-year-olds. The number of respondents in each age subgroup ranged between 84 and 462, and each of these contained approximately equal numbers of male and female subjects, except in the oldest age subgroup, which contained more female than male subjects. After adjustment for non-age-related inter-survey differences, the relationship between the $\alpha$-tocopherol:cholesterol ratio and age was significant and direct $(P=0.006)$, that between the $\gamma$-tocopherol:cholestrol ratio and age was significant and inverse $(P=0.006)$ and that between the $\alpha$-tocopherol: $\gamma$-tocopherol ratio and age was significant and inverse $(P<0.0001)$.

were more likely to have a relatively high $\gamma$-tocopherol and high $\gamma$-tocopherol: $\alpha$-tocopherol ratio than those who did not. Women who had relatively high $\gamma$-tocopherol levels and high $\gamma$-tocopherol: $\alpha$-tocopherol ratios were the most likely to have at least two out of the three indicators of obesity (raised BMI, raised waist circumference, raised waist:hip ratio). There was no significant relationship between any of the anthropometry measures and plasma $\alpha$-tocopherol concentrations.

\section{Indicators of obesity in men aged $\geq 65$ years old}

There were $63 \%$ of men with a BMI of at least $25 \mathrm{~kg} / \mathrm{m}^{2}$, while $60 \%$ had a waist circumference of at least $0.94 \mathrm{~m}$. The waist:hip ratio was high in $26 \%$ of the men. Values for all three indicators of obesity were raised in $49 \%$ of the men.

Table 1 shows that among men, none the three indices of vitamin $\mathrm{E}$ was associated with the indicators of obesity except for the moderately significant relationships between body weight or BMI and $\gamma$-tocopherol and between body weight and the $\gamma$-tocopherol: $\alpha$-tocopherol ratio.

\section{Indicators of obesity in women aged 35-64 years}

There were $59 \%$ of women with BMI of at least $25 \mathrm{~kg} / \mathrm{m}^{2}$, while $60 \%$ had a waist circumference at least $0.80 \mathrm{~m}$ and $33 \%$ had a waist circumference of at least $0.88 \mathrm{~m}$. The waist:hip ratio was at least 0.80 in $47 \%$ of the women. All of the indices of obesity shown in Table 2 (body weight, BMI, waist circumference, and waist:hip ratio, were significantly directly correlated with plasma $\gamma$-tocopherol and with the $\gamma$-tocopherol: $\alpha$-tocopherol ratio, but none was significantly correlated with plasma $\alpha$-tocopherol. All three indices of obesity were above the defined cut-off points in $25 \%$ of these women (see Table 2), and there was a significant direct correlation between $\gamma$-tocopherol 
Table 1. Adjusted parameter estimates of regression between anthropometric and vitamin E status indices in National Diet and Nutrition Surveys in free-living female and male subjects $\geq 65$ years old*

\begin{tabular}{|c|c|c|c|c|c|c|c|c|c|}
\hline \multirow[t]{2}{*}{ Anthropometry (outcome measures) } & \multicolumn{3}{|c|}{$\log _{e}(\alpha$-tocopherol $)$} & \multicolumn{3}{|c|}{$\log _{e}(\gamma$-tocopherol $)$} & \multicolumn{3}{|c|}{$\gamma$-Tocopherol: $\alpha$-tocopherol } \\
\hline & Slope & SE & $P$ & Slope & SE & $P$ & Slope & SE & $P$ \\
\hline \multicolumn{10}{|l|}{ Female ( $n$ 331-335) } \\
\hline Weight (kg) & -1.4 & $3 \cdot 1$ & 0.6 & 2.4 & 1.7 & 0.2 & 34.3 & 21.9 & $0 \cdot 1$ \\
\hline Mid-upper-arm circumference (cm) & -0.2 & 0.96 & 0.9 & $1 \cdot 1$ & 0.5 & 0.03 & $15 \cdot 8$ & $6 \cdot 8$ & 0.02 \\
\hline $\mathrm{BMI}\left(\mathrm{kg} / \mathrm{m}^{2}\right)($ reference $\leq 25) \geq 25 \dagger$ & 0.5 & $0.2-1.6$ & 0.2 & 1.4 & $0 \cdot 8-2 \cdot 7$ & 0.2 & 1.06 & $0.98-1.16$ & 0.1 \\
\hline \multicolumn{10}{|l|}{ Waist circumference $(\mathrm{m}) \dagger$} \\
\hline Action level 1 (reference $<0.80) \geq 0.80$ & 0.5 & $0.1-1.8$ & 0.3 & $2 \cdot 0$ & $0.97-3.96$ & 0.06 & 1.11 & $1.00-1.23$ & 0.05 \\
\hline Action level 2 (reference $<0.88) \geq 0.88$ & 0.6 & $0.2-1 \cdot 7$ & 0.3 & $2 \cdot 6$ & $1.4-4.7$ & 0.003 & 1.16 & $1.07-1.26$ & 0.0006 \\
\hline Waist:hip ratio (reference $<0.80) \geq 0.80$ & 0.5 & $0.2-1.7$ & 0.3 & $2 \cdot 3$ & $1 \cdot 2-4.5$ & 0.02 & $1 \cdot 15$ & $1.04-1 \cdot 27$ & 0.005 \\
\hline $\begin{array}{l}\text { Nos. of indicators of obesity } \\
(\text { reference }<2) \geq 2\end{array}$ & 0.4 & $0.1-1 \cdot 4$ & 0.1 & $3 \cdot 0$ & $1 \cdot 6-5 \cdot 8$ & 0.0006 & $1 \cdot 20$ & $1.09-1.31$ & 0.0002 \\
\hline \multicolumn{10}{|l|}{ Male $(n 369-375)$} \\
\hline Weight $(\mathrm{kg})$ & -0.31 & 2.5 & 0.9 & 3.4 & 1.4 & 0.01 & 37.9 & $18 \cdot 2$ & 0.04 \\
\hline Mid-upper-arm circumference (cm) & 0.3 & 0.7 & 0.7 & 0.4 & 0.4 & 0.3 & 2.6 & $5 \cdot 0$ & 0.6 \\
\hline $\mathrm{BMI}\left(\mathrm{kg} / \mathrm{m}^{2}\right)($ reference $\leq 25) \geq 25 \dagger$ & $1 \cdot 2$ & $0.5-3.2$ & 0.7 & 1.7 & $1 \cdot 0-2 \cdot 9$ & 0.05 & 1.06 & $0.99-1.14$ & 0.1 \\
\hline \multicolumn{10}{|l|}{ Waist circumference $(\mathrm{cm}) \dagger$} \\
\hline Action level 1 (reference $<0.94) \geq 0.94$ & 0.7 & $0.2-1 \cdot 7$ & 0.4 & $1 \cdot 2$ & $0.7-2.1$ & 0.5 & 1.03 & $0.96-1.11$ & 0.4 \\
\hline Action level 2 (reference $<1.02) \geq 1.02$ & 0.6 & $0.2-1.5$ & 0.3 & 1.3 & $0.8-2 \cdot 2$ & 0.3 & 1.05 & $0.98-1.13$ & 0.2 \\
\hline Waist:hip ratio (reference $<0.95) \geq 0.95 \dagger$ & 0.7 & $0.3-1.7$ & 0.4 & $1 \cdot 3$ & $0.8-2 \cdot 2$ & 0.3 & 1.03 & $0.97-1.11$ & 0.4 \\
\hline $\begin{array}{l}\text { Nos. of indicators of obesity } \\
(\text { reference }<2) \geq 2 \dagger\end{array}$ & 0.5 & $0.2-1.4$ & 0.2 & $1 \cdot 1$ & $0.6-1.7$ & 0.9 & 1.02 & $0.95-1.09$ & 0.6 \\
\hline
\end{tabular}

* For details of subjects and procedures, see p. 138.

†Odds ratio and $95 \% \mathrm{Cl}$. Adjusted for age, plasma total cholesterol concentrations and plasma fasting triacylglycerol and excluding those taking vitamin E supplements. The three 'indicators of obesity' referred to in the last line of each section comprised BMI index, waist circumference at action level 2, and waist:hip ratio, all using the dichotomous cut-off points as indicated in the Table.

and the number of obesity indices above the cut-off points (Table 2).

\section{Indicators of obesity in men aged 35-64 years}

In these men, $71 \%$ had a BMI of at least $25 \mathrm{~kg} / \mathrm{m}^{2}$, while $59 \%$ had a waist circumference at least $0.94 \mathrm{~m}$ and $33 \%$ had a waist circumference of at least $1.02 \mathrm{~m}$. The waist:hip ratio was at least 0.95 in $31 \%$ of the men. For this age group of men, plasma $\gamma$-tocopherol was directly and highly significantly correlated with all of the indices of obesity (Table 2). All of the indices of obesity shown in Table 2 (body weight, BMI, waist circumference and waist: hip ratio) were also significantly directly correlated with

Table 2. Adjusted parameter estimates of regression between anthropometry and vitamin $E$ status indices in National Diet and Nutrition Surveys in 35-64-year-old female and male subjects*

\begin{tabular}{|c|c|c|c|c|c|c|c|c|c|}
\hline \multirow[t]{2}{*}{ Anthropometry (outcome measures) } & \multicolumn{3}{|c|}{$\log _{e}(\alpha$-tocopherol) } & \multicolumn{3}{|c|}{$\log _{e}(\gamma$-tocopherol) } & \multicolumn{3}{|c|}{$\gamma$-Tocopherol: $\alpha$ tocopherol } \\
\hline & Slope & SE & $P$ & Slope & SE & $P$ & Slope & SE & $P$ \\
\hline \multicolumn{10}{|l|}{ Female $(n 323-325)$} \\
\hline Weight $(\mathrm{kg})$ & -1.7 & $3 \cdot 7$ & 0.7 & $9 \cdot 0$ & 2.5 & 0.0004 & 145 & 38 & 0.0002 \\
\hline $\begin{array}{l}\left.\text { BMI }\left(\mathrm{kg} / \mathrm{m}^{2}\right) \text { (reference } \leq 25\right) \geq 25 \dagger \\
\text { Waist circumference }(\mathrm{m}) \dagger\end{array}$ & 0.8 & $0 \cdot 3,2 \cdot 0$ & 0.6 & $2 \cdot 1$ & $1 \cdot 0,4 \cdot 3$ & 0.04 & $1 \cdot 1$ & $1 \cdot 0,1 \cdot 3$ & 0.02 \\
\hline Action level 1 (reference $<0.80) \geq 0.80$ & 0.6 & $0.2,1.8$ & 0.4 & $2 \cdot 8$ & $1 \cdot 3,5 \cdot 9$ & 0.006 & $1 \cdot 2$ & $1 \cdot 1,1 \cdot 4$ & 0.003 \\
\hline Action level 2 (reference $<0.88) \geq 0.88$ & 0.7 & $0.3,1.9$ & 0.5 & $6 \cdot 0$ & $2 \cdot 6,14 \cdot 0$ & $<0.0001$ & 1.3 & $1 \cdot 1,1.4$ & $<0.0001$ \\
\hline Waist:hip ratio (reference $<0.80$ ) $\geq 0.80 \dagger$ & 1.0 & $0.4,2.7$ & 0.9 & $2 \cdot 3$ & $1 \cdot 1,4 \cdot 6$ & 0.03 & $1 \cdot 1$ & $1 \cdot 0,1 \cdot 2$ & 0.05 \\
\hline $\begin{array}{l}\text { Nos. of indicators of obesity } \\
\text { (reference }<2) \geq 2\end{array}$ & 0.9 & $0 \cdot 3,2 \cdot 4$ & 0.9 & 4.5 & $2 \cdot 0,9 \cdot 8$ & 0.0002 & $1 \cdot 2$ & $1 \cdot 1,1 \cdot 4$ & 0.0005 \\
\hline \multicolumn{10}{|l|}{ Male (n 296-299) } \\
\hline Weight (kg) & $9 \cdot 0$ & $3 \cdot 0$ & 0.003 & $12 \cdot 3$ & $3 \cdot 2$ & 0.0002 & $14 \cdot 0$ & 48.9 & $0 \cdot 8$ \\
\hline $\begin{array}{l}\mathrm{BMI}\left(\mathrm{kg} / \mathrm{m}^{2}\right)(\text { reference } \leq 25) \geq 25 \dagger \\
\text { Waist circumference }(\mathrm{m}) \dagger\end{array}$ & $3 \cdot 3$ & $1 \cdot 3,8 \cdot 6$ & 0.01 & $4 \cdot 1$ & $1 \cdot 4,11 \cdot 7$ & 0.009 & 1.0 & $0 \cdot 9,1 \cdot 2$ & 0.9 \\
\hline Action level $1($ reference $<0.94) \geq 0.94$ & $2 \cdot 8$ & $1 \cdot 2,6 \cdot 9$ & 0.02 & $6 \cdot 9$ & $2 \cdot 5,19 \cdot 2$ & 0.0002 & $1 \cdot 1$ & $0.9,1.2$ & 0.3 \\
\hline Action level $2($ reference $<1.02) \geq 1.02$ & $2 \cdot 6$ & $1 \cdot 0,6 \cdot 5$ & 0.04 & 8.4 & $2 \cdot 9,24.4$ & $<0.0001$ & $1 \cdot 1$ & $0.98,1.3$ & 0.09 \\
\hline Waist:hip ratio (reference $<0.95) \geq 0.95 \dagger$ & 3.9 & $1.5,10 \cdot 1$ & 0.01 & $6 \cdot 2$ & $2 \cdot 2,17 \cdot 7$ & 0.0007 & $1 \cdot 1$ & $0.9,1.2$ & 0.5 \\
\hline $\begin{array}{l}\text { Nos. of indicators of obesity } \\
(\text { reference }<2) \geq 2\end{array}$ & $2 \cdot 7$ & $1 \cdot 1,6 \cdot 6$ & 0.03 & $5 \cdot 7$ & $2 \cdot 1,15 \cdot 6$ & 0.0007 & $1 \cdot 1$ & $0.97,1.3$ & $0 \cdot 1$ \\
\hline
\end{tabular}

${ }^{*}$ For details of subjects and procedures, see p. 138.

†Odds ratio and $95 \% \mathrm{Cl}$. Adjusted for age, gender, and plasma total cholesterol concentrations and excluding those taking vitamin $\mathrm{E}$ supplements. The three 'indicators of obesity' referred to in the last line of each section comprised BMI, waist circumference at action level 2, and waist:hip ratio, all using the dichotomous cut-off points as indicated in the Table. 
plasma $\alpha$-tocopherol, and the relationships between the obesity indices and the $\gamma$-tocopherol: $\alpha$-tocopherol ratio were weaker, and failed to reach conventional significance.

\section{Indicators of obesity in women aged 19-34 years}

The number of subjects in the youngest adult age group (19-34 years old) was smaller than that in the older categories ( $\geq 65$ and 35-64 years old); therefore the statistical significance of the relationships was expected to be less.

In these young women, $43 \%$ had a BMI of at least $25 \mathrm{~kg} /$ $\mathrm{m}^{2}$, while $42 \%$ had a waist circumference at least $0.80 \mathrm{~m}$ and $19 \%$ had a waist circumference of at least $0.88 \mathrm{~m}$. The waist:hip ratio was at least 0.82 in $7 \%$ of the women. Table 3 shows that in this age group, plasma $\alpha-$ tocopherol was directly related to two of the obesity indices body weight and BMI, and $\gamma$-tocopherol was directly related to body weight alone, whereas none of the plasma vitamin $\mathrm{E}$ indices was significantly related to waist circumference and to waist:hip ratio.

\section{Indicators of obesity in men aged 19-34 years}

In the youngest men $56 \%$ had a BMI of at least $25 \mathrm{~kg} / \mathrm{m}^{2}$, while $34 \%$ had a waist circumference of at least $0.94 \mathrm{~m}$ and $17 \%$ had a waist circumference of at least $1.02 \mathrm{~m}$. Only $8 \%$ had a waist:hip ratio of at least 0.95 . Table 3 shows that more than half of the indices of obesity were significantly correlated directly with plasma $\alpha$-tocopherol and half were also correlated directly with plasma $\gamma$-tocopherol in this group. However, the $\gamma$-tocopherol: $\alpha$-tocopherol ratio was not significantly correlated with any of the indices of obesity here.

\section{Indicators of obesity in young people}

The results in Table 4 suggest that in the age groups up to 18 years (by comparison with the adult respondents), the relationships between obesity indices and those of vitamin E status appeared attenuated, although it should be noted that there were fewer indices of obesity measured in this age group. In the 4-18-year-old age group, there was limited evidence for an inverse correlation between the anthropometric indices of obesity and $\alpha$-tocopherol concentration, and of a direct correlation between the anthopometric indices and $\gamma$-tocopherol concentration or the $\gamma$-tocophero1: $\alpha$-tocopherol ratio (particularly in girls), but this was significant only for mid-upper-arm circumference for the $\gamma$-tocopherol indices. For the survey on toddlers (1.5-4.5 years old), there were no significant relationships nor consistent trends, although unfortunately, upper-arm circumference was not measured in this survey.

\section{Biochemical indicators of nutritional status}

Tables 5 and 6 address the question of relationships with other biochemical status indices in each of the age groups and surveys in turn. As seen in Table 5, $\alpha$-tocopherol increased with improving nutrient status for all micronutrients tested, whereas $\gamma$-tocopherol tended to decrease, and the $\gamma$-tocopherol: $\alpha$ tocopherol ratio also tended to decrease. This remained so whether or not users of vitamin E supplements or indeed of all dietary supplements (results not shown) were eliminated from the calculation. It was equally strong for male and female subjects separately (Table 5) and for male and female subjects combined (results not shown). The inverse relationship between $\gamma$-tocopherol and the other vitamin indices was similar for the water-soluble as for the fat-soluble vitamin indices (Table 5). Other

Table 3. Adjusted parameter estimates of regression between anthropometry and vitamin E status indices in National Diet and Nutrition Surveys in 19-34-year-old female and male subjects*

\begin{tabular}{|c|c|c|c|c|c|c|c|c|c|}
\hline \multirow[t]{2}{*}{ Anthropometry (outcome measures) } & \multicolumn{3}{|c|}{$\log _{e}(\alpha$-tocopherol) } & \multicolumn{3}{|c|}{$\log _{e}(\gamma$-tocopherol) } & \multicolumn{3}{|c|}{$\gamma$-Tocopherol: $\alpha$-tocopherol } \\
\hline & Slope & SE & $P$ & Slope & SE & $P$ & Slope & SE & $P$ \\
\hline \multicolumn{10}{|l|}{ Female (n 160-162) } \\
\hline Weight $(\mathrm{kg})$ & $12 \cdot 0$ & $4 \cdot 6$ & 0.01 & $9 \cdot 5$ & 3.7 & 0.01 & $-5 \cdot 1$ & $65 \cdot 0$ & 0.9 \\
\hline $\begin{array}{l}\text { BMI }\left(\mathrm{kg} / \mathrm{m}^{2}\right)(\text { reference } \leq 25) \geq 25 \dagger \\
\text { Waist circumference }(\mathrm{m}) \dagger\end{array}$ & $9 \cdot 7$ & $2 \cdot 0,47 \cdot 3$ & 0.005 & $2 \cdot 8$ & $0 \cdot 8,10 \cdot 2$ & $0 \cdot 1$ & 0.9 & $0 \cdot 7,1 \cdot 1$ & 0.3 \\
\hline Action level 1 (reference $<0.80) \geq 0.80$ & $4 \cdot 1$ & $0.9,19 \cdot 4$ & 0.07 & $2 \cdot 7$ & $0.7,9 \cdot 7$ & $0 \cdot 1$ & 0.9 & $0 \cdot 8,1 \cdot 2$ & 0.6 \\
\hline Waist:hip ratio (reference $<0.80$ ) $\geq 0.80$ & $2 \cdot 7$ & $0.5,13 \cdot 7$ & $0 \cdot 2$ & 0.9 & $0 \cdot 2,3 \cdot 0$ & $0 \cdot 8$ & 0.9 & $0 \cdot 7,1 \cdot 1$ & $0 \cdot 2$ \\
\hline $\begin{array}{l}\text { Nos. of indicators of obesity } \\
\text { (reference }<2) \geq 2\end{array}$ & $3 \cdot 6$ & $0 \cdot 6,21 \cdot 1$ & $0 \cdot 2$ & $2 \cdot 6$ & $0.6,11 \cdot 3$ & $0 \cdot 2$ & $1 \cdot 0$ & $0.8,1.3$ & 0.8 \\
\hline \multicolumn{10}{|l|}{ Male (n 127-128) } \\
\hline Weight $(\mathrm{kg})$ & $13 \cdot 7$ & $5 \cdot 1$ & 0.008 & $9 \cdot 2$ & 3.6 & 0.01 & $52 \cdot 1$ & $58 \cdot 3$ & 0.4 \\
\hline $\begin{array}{l}\left.\text { BMI }\left(\mathrm{kg} / \mathrm{m}^{2}\right) \text { (reference } \leq 25\right) \geq 25 \dagger \\
\text { Waist circumference }(\mathrm{m}) \dagger\end{array}$ & $9 \cdot 0$ & $1 \cdot 7,48 \cdot 0$ & 0.01 & $3 \cdot 0$ & $0.9,10.5$ & 0.08 & $1 \cdot 0$ & $0.9,1.2$ & 0.8 \\
\hline Action level 1 (reference $<0.94) \geq 0.94$ & 4.9 & $0.98,24.2$ & 0.05 & $5 \cdot 0$ & $1 \cdot 3,18 \cdot 8$ & 0.02 & $1 \cdot 1$ & $0.9,1.3$ & 0.3 \\
\hline Waist:hip ratio (reference $<0.95$ ) $\geq 0.95 \ddagger$ & & & & & & & & & \\
\hline $\begin{array}{l}\text { Nos. of indicators of obesity } \\
\text { (reference }<2) \geq 2\end{array}$ & $3 \cdot 7$ & $0 \cdot 3,51 \cdot 2$ & 0.3 & $4 \cdot 7$ & $0 \cdot 6,39 \cdot 3$ & 0.2 & $1 \cdot 0$ & $0 \cdot 8,1 \cdot 4$ & $0 \cdot 8$ \\
\hline
\end{tabular}

${ }^{*}$ For details of subjects and procedures, see p. 138.

†Odds ratio and $95 \% \mathrm{Cl}$. Adjusted for age, gender and plasma total cholesterol concentrations. The three 'indicators of obesity' referred to in the last line of each section comprised BMI, waist circumference at action level 2, and waist:hip ratio, all using the dichotomous cut-off points as indicated in the Table.

$\ddagger$ There were only ten cases with waist:hip ratio of $\geq 0.95$, hence odds ratios were not calculated. 
Table 4. Linear regression analysis of anthropometry and vitamin E status indices in National Diet and Nutrition Surveys on 4-18 and 1.54.5-year-olds*

\begin{tabular}{|c|c|c|c|c|c|c|c|c|c|}
\hline \multirow[t]{2}{*}{ Anthropometry (outcome measures) } & \multicolumn{3}{|c|}{$\log _{e}(\alpha$-tocopherol) } & \multicolumn{3}{|c|}{$\log _{e}(\gamma$-tocopherol) } & \multicolumn{3}{|c|}{$\gamma$-Tocopherol: $\alpha$-tocopherol } \\
\hline & Slope & SE & $P \dagger$ & Slope & SE & $P+$ & Slope & SE & $P+$ \\
\hline \multicolumn{10}{|l|}{ Survey of $4-18$-year-olds: female, $n 448$} \\
\hline Body weight & -6.4 & $25 \cdot 6$ & 0.8 & 14.5 & $10 \cdot 8$ & 0.2 & 189 & 153 & 0.2 \\
\hline $\mathrm{BMI}$ & -0.003 & 0.009 & 0.7 & 0.004 & 0.004 & 0.3 & 0.07 & 0.05 & 0.2 \\
\hline Mid-upper-arm circumference $(\mathrm{cm})$ & 0.17 & 0.9 & 0.9 & 0.75 & 0.37 & 0.04 & $10 \cdot 4$ & $5 \cdot 2$ & 0.05 \\
\hline \multicolumn{10}{|l|}{ Survey of $4-18$-year-olds: male, $n 477$} \\
\hline Body weight & -45 & 27 & 0.09 & $-5 \cdot 3$ & 11.4 & 0.6 & 44 & 143 & 0.8 \\
\hline BMI & -0.018 & 0.008 & 0.02 & 0.0002 & 0.003 & $1 \cdot 0$ & 0.042 & 0.043 & 0.3 \\
\hline Mid-upper-arm circumference $(\mathrm{cm})$ & -1.0 & 0.8 & 0.2 & 0.23 & 0.34 & 0.5 & $5 \cdot 1$ & $4 \cdot 3$ & 0.2 \\
\hline \multicolumn{10}{|c|}{ Survey of $1.5-4.5$-year-olds: male and female combined, $n 597-599$} \\
\hline Body weight & +0.2 & 0.4 & 0.6 & -0.16 & 0.16 & 0.3 & $-2 \cdot 6$ & 1.8 & 0.2 \\
\hline BMI & 0.14 & 0.35 & 0.7 & -0.07 & 0.13 & 0.6 & -0.8 & 1.5 & 0.6 \\
\hline
\end{tabular}

${ }^{*}$ For details of subjects and procedures, see p. 138.

$\dagger P$ values for linear regression are adjusted for age, gender, plasma total cholesterol and plasma triacylglycerol, and exclude vitamin $E$ supplement-users.

biochemical indices, such as plasma $\beta$-carotene and erythrocyte reductase activation coefficient (an index of riboflavin status) were also significantly related to the vitamin $\mathrm{E}$ indices (results not shown). Table 6 shows that an analogous pattern of relationships involving the vitamin $\mathrm{E}$ indices and the other vitamin indices (direct for $\alpha$-tocopherol; generally inverse for the two indices with $\gamma$-tocopherol in the numerator) was also observed within the NDNS datasets for 35-64-, 19-34-, 4-18- and 1.5-4.5year-olds. All the four vitamins indices shown in the Tables had significant relationships with the vitamin $\mathrm{E}$ indices in at least one instance, and the same was true for $\beta$-carotene and erythrocyte reductase activation coefficient (results not shown).

\section{Estimates of nutrient intakes}

Tables 7 and 8 explore the vitamin $\mathrm{E}$ status relationships with a selection of estimated nutrient intakes in the four surveys. In general the relationships were stronger and more consistent with selected micronutrients than for macronutrients such as food energy, total fat and total protein in the diet. The intake of $\alpha$-tocopherol was frequently directly related to a number of markers of a relatively 'healthy' diet, such as intrinsic sugars, fibre, fat- and water-soluble vitamins, and potassium, and was inversely related to sucrose. $\gamma$-Tocopherol was related in the opposite direction with the nutrients that are generally associated with a 'healthy' diet, and the $\gamma$-tocopherol: $\alpha$ tocopherol ratio was inversely related with the 'healthy' nutrients. For several of the age-gender groups there was a direct relationship between $\gamma$-tocopherol or the $\gamma$-tocopherol: $\alpha$-tocopherol ratio and MUFA, whereas $\alpha$-tocopherol was inversely related to MUFA intakes. Tables 7 and 8 show that the correlation patterns for nutrient intakes in the surveys on 4-18and $1 \cdot 5-4 \cdot 5$-year-olds were generally similar to those seen in the free-living $\geq 65$ - and 35-64-year-olds, whereas they were less consistent in the 19-34-year-olds.

\section{Estimates of intakes of selected food groups}

Table 9 depicts some relationships between plasma vitamin $\mathrm{E}$ indices and selected food group choices in all four surveys. Of more than 100 food groups included in the survey reports, only a small selection of food groups were selected and combined to reflect certain 'healthy' and 'unhealthy' dietary choices, based on the nutrient intake patterns observed in Tables 7 and 8. Those food

Table 5. Linear regression analysis of vitamin E status indices and other vitamin status indices in National Diet and Nutrition Surveys on freeliving subjects aged $\geq 65$ years*

\begin{tabular}{|c|c|c|c|c|c|c|c|c|c|}
\hline \multirow[t]{2}{*}{ Vitamin status indices (outcome measures) } & \multicolumn{3}{|c|}{$\log _{e}(\alpha$-tocopherol) } & \multicolumn{3}{|c|}{$\log _{e}(\gamma$-tocopherol) } & \multicolumn{3}{|c|}{$\gamma$-Tocopherol: $\alpha$-tocopherol } \\
\hline & Slope & SE & $P+$ & Slope & SE & $P+$ & Slope & SE & $P+$ \\
\hline $\log _{e}($ plasma retinol) $(\mu \mathrm{mol} / \mathrm{l})$ & $0 \cdot 22$ & 0.07 & 0.001 & -0.028 & 0.038 & 0.5 & $-1 \cdot 20$ & 0.50 & 0.02 \\
\hline $\log _{e}($ plasma 25-OHD) (nmol/l) & $0 . \overline{67}$ & 0.12 & $<0.0001$ & -0.05 & 0.07 & 0.4 & -2.62 & 0.89 & 0.003 \\
\hline Plasma vitamin $\mathrm{C}(\mu \mathrm{mol} / \mathrm{l})$ & $21 \cdot 3$ & $6 \cdot 7$ & 0.001 & -11.9 & $3 \cdot 6$ & 0.001 & -207 & 47 & 0.0001 \\
\hline $\log _{e}($ serum folate) $(\mathrm{nmol} / \mathrm{l})$ & 0.58 & $0 \cdot 17$ & 0.0008 & -0.11 & 0.09 & 0.2 & $-2 \cdot 71$ & $1 \cdot 24$ & 0.03 \\
\hline \multicolumn{10}{|l|}{ Male $(n 369-375)$} \\
\hline $\log _{e}($ plasma retinal) $(\mu \mathrm{mol} / \mathrm{l})$ & 0.15 & 0.06 & 0.01 & -0.05 & 0.03 & 0.08 & $-1 \cdot 26$ & 0.40 & 0.002 \\
\hline $\log _{e}$ (plasma 25-OHD) (nmol/l) & 0.40 & 0.12 & 0.001 & 0.025 & 0.067 & 0.7 & -0.79 & 0.90 & 0.4 \\
\hline Plasma vitamin C $(\mu \mathrm{mol} / \mathrm{l})$ & $16 \cdot 9$ & $5 \cdot 2$ & 0.001 & $-7 \cdot 4$ & $2 \cdot 8$ & 0.008 & -150 & 37 & $<0.0001$ \\
\hline $\log _{e}($ serum folate) $(\mathrm{nmol} / \mathrm{l})$ & 0.40 & $0 \cdot 15$ & 0.009 & -0.10 & 0.08 & 0.2 & -2.9 & $1 \cdot 1$ & 0.009 \\
\hline
\end{tabular}

25-OHD, 25-hydroxycholecalciferol.

${ }^{*}$ For details of subjects and procedures, see p. 138.

$\dagger P$ values for linear regression are adjusted for age, gender, plasma total cholesterol and plasma fasting triacylglycerol, and exclude vitamin $\mathrm{E}$-supplement users. 
Table 6. Linear regression analysis of vitamin $\mathrm{E}$ status indices and other vitamin status indices in National Diet and Nutrition Surveys on 19-64-, 4-18- and 1.5-4.5-year-olds*

\begin{tabular}{|c|c|c|c|c|c|c|c|c|c|}
\hline \multirow[t]{2}{*}{ Vitamin status indices (outcome measures) } & \multicolumn{3}{|c|}{$\log _{e}(\alpha$-tocopherol $)$} & \multicolumn{3}{|c|}{$\log _{e}(\gamma$-tocopherol $)$} & \multicolumn{3}{|c|}{$\gamma$-Tocopherol: $\alpha$-tocopherol } \\
\hline & Slope & SE & $P \ddagger$ & Slope & SE & $P \ddagger$ & Slope & SE & $P \ddagger$ \\
\hline \multicolumn{10}{|l|}{ 35-64-year-old female (n 313-325)† } \\
\hline $\log _{e}($ plasma retinol) $(\mu \mathrm{mol} / \mathrm{l})$ & $0 \cdot 23$ & 0.06 & 0.0003 & -0.105 & 0.044 & 0.018 & $-2 \cdot 75$ & 0.65 & $<0.0001$ \\
\hline $\log _{e}$ (plasma 25-OHD) (nmol/l) & 0.056 & 0.128 & 0.7 & -0.059 & 0.089 & 0.5 & -1.41 & $1 \cdot 33$ & 0.3 \\
\hline Plasma vitamin $C(\mu \mathrm{mol} / \mathrm{l})$ & $14 \cdot 1$ & $6 \cdot 6$ & 0.03 & $9 \cdot 1$ & $4 \cdot 6$ & 0.05 & -244 & 67 & 0.0003 \\
\hline $\log _{e}($ serum folate) $(\mathrm{nmol} / \mathrm{l})$ & 0.19 & $0 \cdot 10$ & 0.07 & $-0 \cdot 157$ & 0.071 & 0.03 & $-3 \cdot 18$ & 1.06 & 0.003 \\
\hline \multicolumn{10}{|l|}{ 35-64-year-old male (n 278-299)† } \\
\hline $\log _{e}($ plasma retinol) $(\mu \mathrm{mol} / \mathrm{l})$ & 0.44 & 0.05 & $<0.0001$ & 0.23 & 0.06 & 0.0002 & $-4 \cdot 61$ & 0.88 & $<0.0001$ \\
\hline $\log _{e}($ plasma 25-OHD) (nmol/l) & 0.27 & 0.09 & 0.004 & 0.078 & $0 \cdot 102$ & 0.4 & -4.32 & 1.49 & 0.004 \\
\hline Plasma vitamin $C(\mu \mathrm{mol} / \mathrm{l})$ & $8 \cdot 9$ & $5 \cdot 3$ & $0 \cdot 1$ & -0.77 & 5.9 & 0.9 & -189 & 85 & 0.03 \\
\hline $\log _{e}($ serum folate) $(\mathrm{nmol} / \mathrm{l})$ & $0 \cdot 18$ & 0.09 & 0.03 & -0.13 & 0.09 & $0 \cdot 2$ & $5 \cdot 36$ & $1 \cdot 36$ & 0.0001 \\
\hline \multicolumn{10}{|l|}{ 19-34-year-old female $(n$ 151-162) $\dagger$} \\
\hline $\log _{e}($ plasma retinol) $(\mu \mathrm{mol} / \mathrm{l})$ & 0.34 & 0.09 & 0.0003 & 0.029 & 0.076 & 0.7 & $-3 \cdot 84$ & $1 \cdot 26$ & 0.003 \\
\hline $\log _{e}($ plasma 25-OHD) (nmol/l) & 0.34 & $0 \cdot 19$ & 0.07 & -0.070 & 0.149 & 0.6 & -4.80 & 2.50 & 0.06 \\
\hline \multicolumn{10}{|l|}{ 19-34-year-old male (n 118-128)† } \\
\hline $\log _{e}($ plasma retinol) $(\mu \mathrm{mol} / \mathrm{l})$ & 0.34 & 0.07 & $<0.0001$ & 0.118 & 0.056 & 0.04 & -0.91 & 0.90 & 0.3 \\
\hline $\log _{e}($ plasma 25-OHD) (nmol/l) & 0.71 & 0.19 & 0.0002 & 0.37 & 0.14 & 0.008 & -0.058 & $2 \cdot 24$ & 0.9 \\
\hline Plasma vitamin C $(\mu \mathrm{mol} / \mathrm{l})$ & $14 \cdot 0$ & 9.5 & $0 \cdot 1$ & -0.093 & $6 \cdot 8$ & 1.0 & -104 & 107 & 0.3 \\
\hline $\log _{e}($ serum folate) $(\mathrm{nmol} / \mathrm{l})$ & 0.39 & $0 \cdot 15$ & 0.009 & $0 \cdot 115$ & $0 \cdot 106$ & 0.3 & -0.39 & $1 \cdot 70$ & 0.8 \\
\hline \multicolumn{10}{|c|}{ 4-18-year-old, male and female combined ( $n$ 912-924) } \\
\hline $\log _{e}($ plasma retinol) $(\mu \mathrm{mol} / \mathrm{l})$ & 0.29 & 0.04 & $<0.0001$ & 0.017 & 0.019 & 0.4 & -0.50 & 0.25 & 0.05 \\
\hline $\log _{e}($ plasma 25-OHD) (nmol/l) & 0.38 & 0.09 & $<0.0001$ & -0.09 & 0.04 & 0.02 & -2.42 & 0.52 & $<0.0001$ \\
\hline Plasma vitamin $C(\mu \mathrm{mol} / \mathrm{l})$ & $16 \cdot 6$ & $4 \cdot 4$ & 0.0001 & $-5 \cdot 1$ & $1 \cdot 8$ & 0.007 & -111 & 25 & $<0.0001$ \\
\hline $\log _{e}($ serum folate) $(\mathrm{nmol} / \mathrm{l})$ & $0 \cdot 15$ & 0.07 & 0.04 & -0.054 & 0.031 & 0.08 & -0.96 & 0.41 & 0.02 \\
\hline \multicolumn{10}{|c|}{ 1.5-4.5-year-old, male and female combined ( $n 596-624)$} \\
\hline $\log _{e}($ plasma retinol) $(\mu \mathrm{mol} / \mathrm{l})$ & 0.28 & 0.05 & $<0.0001$ & -0.018 & 0.021 & 0.4 & -0.70 & 0.25 & 0.006 \\
\hline $\log _{e}($ plasma 25-OHD) (nmol/l) & 0.34 & 0.08 & $<0.0001$ & -0.057 & 0.030 & 0.06 & $-1 \cdot 37$ & 0.36 & 0.0002 \\
\hline Plasma vitamin C ( $\mu \mathrm{mol} / \mathrm{l})$ & $39 \cdot 3$ & $7 \cdot 1$ & $<0.0001$ & -3.95 & $2 \cdot 70$ & $0 \cdot 1$ & -106 & 32 & 0.001 \\
\hline $\log _{e}($ serum folate) $(\mathrm{nmol} / \mathrm{l})$ & 0.14 & 0.12 & 0.2 & -0.144 & 0.044 & 0.001 & -1.93 & 0.53 & 0.0003 \\
\hline
\end{tabular}

25-OHD, 25-hydroxycholecalciferol.

${ }^{\star}$ For details of subjects and procedures, see p. 141.

†The 35-64- and 19-34-year-old age groups are subsets of the survey on 19-64-year-olds.

$\ddagger P$ values for linear regression are adjusted for age, gender, plasma total cholesterol and for plasma triacylglycerol where available, and exclude vitamin $E$ supplement-users.

choices that are commonly classified as 'healthy' (i.e. use of polyunsaturated fats and oils; fresh fruit and fruit juices) were usually directly correlated with plasma $\alpha$-tocopherol, and were inversely correlated with plasma $\gamma$-tocopherol and with the $\gamma$-tocopherol: $\alpha$-tocopherol ratio. The reverse was true for the 'less healthy' food choices comprising non-PUFA-rich fats and spreads, and sugar. Non-fruit soft drinks also fell into the latter category (results not shown).

\section{Effects of smoking}

Within the NDNS free-living $\geq 65$-year-old sample, $16 \%$ admitted to being current (self-reported) smokers (cigarette, pipe or cigar). Compared with the self-reported non-smokers, after adjustment for age, gender, plasma total cholesterol and plasma fasting triacylglycerol, the smokers had significantly lower plasma concentrations of $\alpha$-tocopherol (32.4 v. 34. $2 \mu \mathrm{mol} / 1,704 \mathrm{df}, P=0.0002)$, but their concentrations of $\gamma$-tocopherol and the $\gamma$-tocopherol: $\alpha$ tocopherol ratio did not differ significantly from those of non-smokers $(P=0.2$ and 0.5 respectively). Within the survey on adults, $48 \%$ admitted to being smokers, and they had lower plasma $\alpha$-tocopherol concentrations than the self-reported non-smokers (18.6 v. $20.7 \mu \mathrm{mol} / 1, P<0.0001)$ after adjusting for age, gender and plasma cholesterol. Unlike the survey on $\geq 65$-year-olds, in the survey on adults plasma $\gamma$-tocopherol concentration was also lower in the smokers (1.14 v. $1.23 \mu \mathrm{mol} / 1, P=0.01)$, whereas the ratio of the two indices was not significantly different between smokers and non-smokers. Within the NDNS 11-18-year-old subgroup of the survey on 4-18-year-olds there were $18 \%$ self-reported smokers, but these did not differ significantly from the non-smokers for any of the three plasma tocopherol indices studied $(P=0 \cdot 2-1 \cdot 0)$. Relationships between the three vitamin $\mathrm{E}$ status indices and the outcome (independent variable) indices, including those describing the anthropometric characteristics, did not differ significantly between the smokers and non-smokers for any of the three surveys where smokers were identified (results not shown).

\section{Discussion}

The focus of the present study was the pattern of relationships between the two blood vitamin E status indices, $\alpha$ and $\gamma$-tocopherol, and a range of status and dietary 
Table 7. Linear regression analysis of vitamin E status indices and selected nutrient intakes in National Diet and Nutrition Surveys in free-living subjects aged $\geq 65$ years*

\begin{tabular}{|c|c|c|c|c|c|c|c|c|c|}
\hline \multirow{2}{*}{$\begin{array}{l}\text { Nutrient intakes } \\
\text { (outcome measures) }\end{array}$} & \multicolumn{3}{|c|}{$\log _{e}(\alpha$-tocopherol) } & \multicolumn{3}{|c|}{$\log _{e}(\gamma$-tocopherol $)$} & \multicolumn{3}{|c|}{$\gamma$-Tocopherol: $\alpha$-tocopherol } \\
\hline & Slope & SE & $P \dagger$ & Slope & SE & $P \dagger$ & Slope & SE & $P \dagger$ \\
\hline \multicolumn{10}{|l|}{ Female (n 319-322) } \\
\hline Food energy $(\mathrm{kJ} / \mathrm{d})$ & 1028 & 377 & 0.007 & -252 & 207 & 0.2 & -6957 & 2706 & 0.01 \\
\hline $\begin{array}{l}\text { Monounsaturated } \\
\text { fatty acids }(\mathrm{g} / \mathrm{d})\end{array}$ & $-2 \cdot 77$ & 0.91 & 0.002 & 0.82 & 0.40 & 0.09 & $18 \cdot 8$ & 6.5 & 0.004 \\
\hline Extrinsic sugars $(\mathrm{g} / \mathrm{d})$ & -5.57 & $5 \cdot 82$ & 0.3 & 1.14 & $3 \cdot 10$ & 0.7 & $26 \cdot 3$ & $41 \cdot 2$ & 0.5 \\
\hline Intrinsic \& milk sugars $(\mathrm{g} / \mathrm{d})$ & $8 \cdot 3$ & 3.6 & 0.02 & -4.22 & 1.96 & 0.03 & -67 & 26 & 0.009 \\
\hline Fibre $(\mathrm{g} / \mathrm{d})$ & $5 \cdot 1$ & 1.3 & $<0.0001$ & 0.84 & 0.70 & 0.2 & $-19 \cdot 3$ & $9 \cdot 3$ & 0.04 \\
\hline $\log _{e}($ vitamin E) (mg/d) & 0.68 & 0.12 & $<0.0001$ & -0.054 & 0.068 & 0.4 & -2.79 & 0.89 & 0.002 \\
\hline $\log _{e}($ vitamin C) $(\mathrm{mg} / \mathrm{d})$ & -0.013 & 0.9 & 0.9 & -0.22 & 0.09 & 0.02 & -2.55 & 1.26 & 0.04 \\
\hline Potassium (mg/d) & 285 & 122 & 0.02 & -189 & 65 & 0.004 & -2889 & 863 & 0.0009 \\
\hline \multicolumn{10}{|l|}{ Male $(n 361-362)$} \\
\hline Food energy $(\mathrm{kJ} / \mathrm{d})$ & 481 & 479 & 0.3 & 326 & 252 & 0.2 & -169 & 3384 & 0.9 \\
\hline $\begin{array}{l}\text { Monounsaturated fatty } \\
\text { acids }(\mathrm{g} / \mathrm{d})\end{array}$ & 0.20 & 1.11 & 0.9 & 1.99 & 0.57 & 0.0006 & 23 & 7.7 & 0.004 \\
\hline Extrinsic sugars $(g / d)$ & $-18 \cdot 3$ & $7 \cdot 7$ & 0.02 & 1.30 & 4.09 & 0.7 & 78 & 54 & 0.1 \\
\hline Intrinsic and milk sugars $(\mathrm{g} / \mathrm{d})$ & $13 \cdot 2$ & $3 \cdot 2$ & $<0.0001$ & -1.64 & 1.71 & 0.3 & -61 & 23 & 0.007 \\
\hline Fibre $(g / d)$ & 8.0 & 1.6 & $<0.0001$ & 0.33 & 0.86 & 0.7 & -22 & 11 & 0.05 \\
\hline $\log _{e}($ vitamin E) (mg/d) & 0.93 & 0.11 & $<0.0001$ & -0.08 & 0.06 & 0.2 & -3.53 & 0.85 & $<0.0001$ \\
\hline $\log _{e}($ vitamin C) $(\mathrm{mg} / \mathrm{d})$ & 0.50 & $0 \cdot 16$ & 0.002 & -0.14 & 0.09 & 0.1 & -3.08 & $1 \cdot 14$ & 0.007 \\
\hline Potassium (mg/d) & 441 & 128 & 0.0006 & -102 & 68 & 0.1 & -2553 & 902 & 0.005 \\
\hline
\end{tabular}

${ }^{\star}$ For details of procedures, see p. 138.

$\dagger P$ values for linear regression are adjusted for age, gender, BMI, plasma total cholesterol and triacylglycerol (and for food energy except for food energy itself) and exclude vitamin E supplement-users.

intake estimates. These included dietary choices, selected biochemical indices that are influenced both by diet and by physiological factors, and anthropometric measurements, with a particular emphasis on indices of obesity and overweight, which may in turn predict and affect the risk of medical conditions such as metabolic syndrome and type 2 diabetes. The starting point was a re-examination of the commonly held view that $\alpha$ - and $\gamma$-tocopherols should exhibit similar and parallel relationships with most other survey indices, since they are both forms of the same vitamin with similar chemical structures and redox-modulation properties. The $\gamma$-tocopherol: $\alpha$ tocopherol concentration ratio was also examined, for two reasons. First, any contrasts between the two forms of vitamin $\mathrm{E}$ should be revealed most clearly in the concentration ratio. Second, the ratio of the two forms of the vitamin should be less affected by other confounding variables, such as the concentration of other plasma lipids (cholesterol, triacylglycerol) and lipoproteins that are known to influence overall plasma vitamin E concentrations. Wherever the relationships between the tocopherol status indices and outcome (independent variable) anthropometric or biochemical status indices were being explored, plasma cholesterol and (where available) plasma triacylglycerol concentrations were included as dependent covariates in order to adjust for blood lipids, since these are well known to be powerful determinants of the vitamin $\mathrm{E}$ status indices. The regression calculations were also adjusted for the possibly confounding effects of variations in age, gender and of food energy (in the case of specific nutrient and food group intakes).

The decision to exclude supplement users from the present investigation was taken: (1) to avoid the statistical problems associated with highly skewed vitamin E (specifically $\alpha$-tocopherol) intake patterns caused by a minority of subjects with large intakes from supplements; (2) to avoid the confounding effects on metabolism that such high intakes and body burdens of $\alpha$-tocopherol may induce; (3) to confine the present study to a population that differed in this key respect (i.e. use of dietary vitamin E supplements) from the population recently studied in the USA by White et al. (2001).

Previously reported studies of changes in serum or plasma tocopherol levels with age in human populations have yielded divergent results (Vatassery et al. 1983; Behrens \& Madere, 1986). The four surveys in the present study spanned a 10-year period, starting with the survey on toddlers in the early 1990s and ending with the adults survey in 2001-2002, during which time dietary choices and analytical methods had undergone some alterations. However, after adjustment for those inter-survey differences that were not age-related, the present study indicated that there was evidence for a modest increase in the $\alpha$ tocopherol:cholesterol ratio and a modest decrease in the $\gamma$-tocopherol:cholesterol and the $\gamma$-tocopherol: $\alpha$-tocopherol ratios with increasing subject age (Fig. 1).

Although many laboratories now regularly measure both $\alpha$ and $\gamma$-tocopherol in serum or plasma samples, it is often assumed that only the major $(\alpha)$ component or the arithmetic sum of both forms is of interest for measuring vitamin E status or for examining relationships with risk factors. Only a few studies have considered the correlates and predictive properties of $\gamma$-tocopherol as having distinctly different characteristics from those of $\alpha$-tocopherol in human subjects (Handelman et al. 1985; Ascherio et al. 1992; Sinha et al. 1993; Handelman et al. 1994; Vogel et al. 1997; White et al. 2001). There is general agreement that a large increase in intake of $\alpha$-tocopherol results in a 


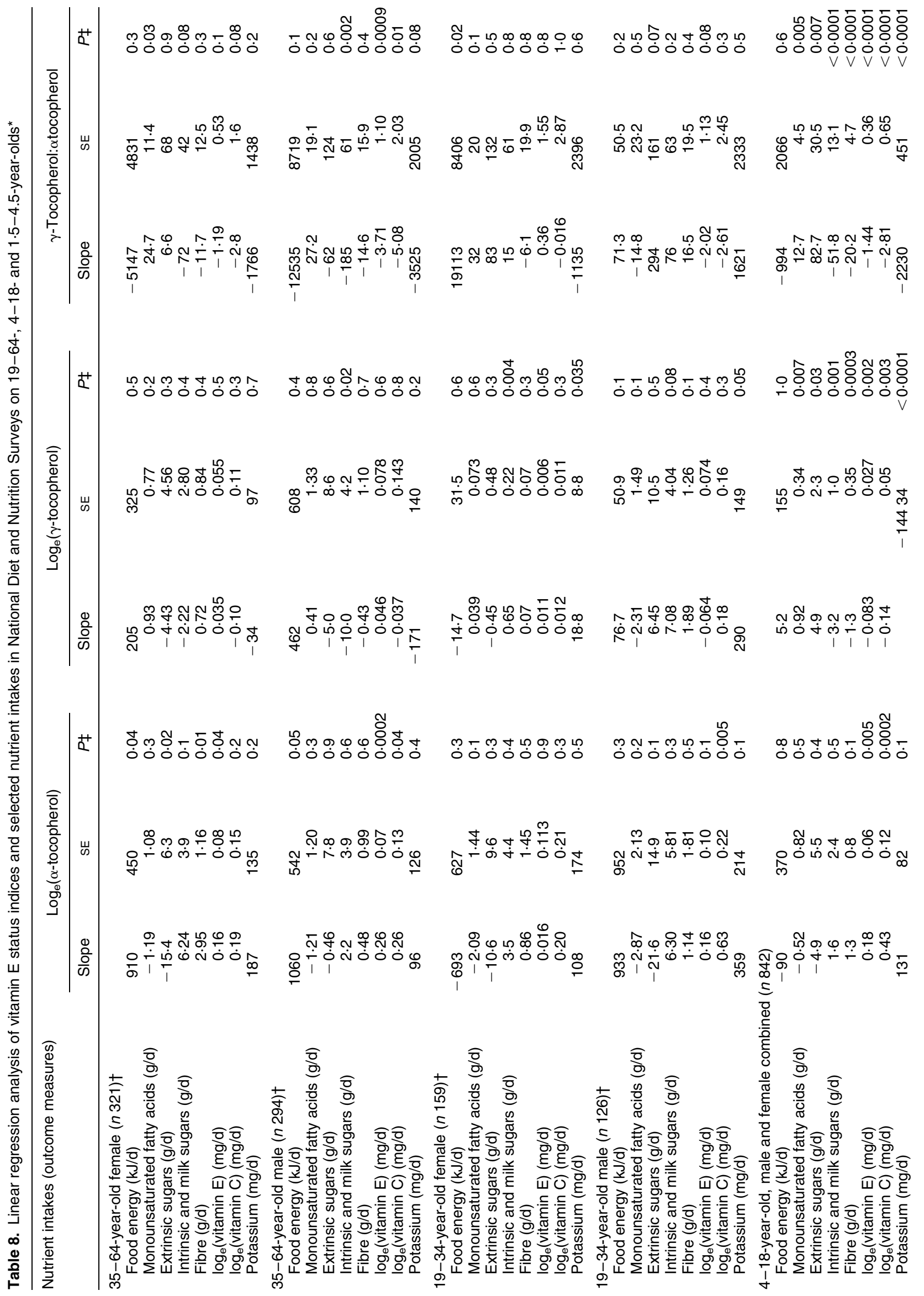


decrease in plasma $\gamma$-tocopherol, probably as a result of increased hepatic turnover of $\gamma$-tocopherol (Blatt et al. 2001; Morinobu et al. 2003). Plasma $\alpha$-tocopherol is not a very reliable indicator of $\alpha$-tocopherol intake over the physiological range; plasma $\gamma$-tocopherol, however, appears to be a better indicator of $\gamma$-tocopherol intake (El-Sohemy et al. 2001). Handelman et al. (1985) have suggested that the $\gamma$-tocopherol: $\alpha$-tocopherol ratio in plasma would be a more satisfactory index to measure compliance in trials of $\alpha$-tocopherol supplementation than plasma $\alpha$-tocopherol per se, and they observed that the ratio of the two forms of vitamin $\mathrm{E}$ changed progressively over a 2-year period of $\alpha$-tocopherol supplementation (Handelman et al. 1985; Baker et al. 1986; Handelman et al. 1994).

The recent study by White et al. (2001) examined the correlates of plasma $\alpha$ - and $\gamma$-tocopherol in postmenopausal US women aged 50-79 years as part of the Women's Health Initiative forty-site disease-prevention trial. They found that plasma $\gamma$-tocopherol was inversely related to plasma $\alpha$-tocopherol, whereas in the present study, plasma $\alpha$-tocopherol was directly related to $\gamma$-tocopherol after adjustment for plasma cholesterol and triacylglycerol in all age groups. White et al. (2001) found that $\alpha$-tocopherol was directly related, and that $\gamma$-tocopherol was inversely related, to intakes of vitamin E (i.e. $\alpha$-tocopherol) from dietary supplements. In their study, plasma $\alpha$-tocopherol was inversely related to BMI, whereas plasma $\gamma$ tocopherol was directly related to this index of obesity. In addition, increased plasma $\alpha$-tocopherol and decreased plasma $\gamma$-tocopherol were both directly related to increased serum retinol and carotenoid concentrations, they were directly related to the use of vitamin $\mathrm{C}$ supplements, to an increased intake of $\alpha$-tocopherol or of dietary fibre from food, and to Hispanic ethnicity. In two other studies of US adults (Sinha et al. 1993; Rock et al. 1997), serum $\alpha$-tocopherol was again directly related to BMI.

Many, but not all of the observations of White et al. (2001) are similar to those of that part of the present study which examined middle-aged and older UK women in the NDNS of $\geq 65$ - and 19-64-year-olds. In these NDNS surveys, not only BMI, but also several other measures of obesity were directly related to plasma $\gamma$-tocopherol. The most consistent and significant relationships were observed for the $\gamma$-tocopherol: $\alpha$-tocopherol ratio (Tables 1, 2 and 3). In the study of White et al. (2001), no significant correlation with waist:hip ratio was observed, whereas in the present study, plasma $\gamma$-tocopherol was significantly (directly) related to waist:hip ratio, in two distinct age groups drawn from two separate surveys. White et al. (2001) speculated that $\alpha$-tocopherol may be preferentially stored in adipose tissue and might, therefore, be depleted from the plasma in relatively obese people. However, studies on rats by Bieri \& Poukka Evarts (1974) and a study of human surgical patients by Burton et al. (1998) both suggested that the $\gamma$-tocopherol: $\alpha$-tocopherol ratio in adipose tissue is higher, not lower, than it is in plasma.

Our present study seems to indicate that the inverse relationship of plasma $\gamma$-tocopherol with the indices of obesity is strongest in older women (i.e. the same age 
Table 9. Linear regression analysis of vitamin E status indices and selected food group intakes in National Diet and Nutrition Surveys in free-living subjects aged $\geq 65$ years and 19-64-, 4-18- and 1.5-4.5-year-olds*

\begin{tabular}{|c|c|c|c|c|c|c|c|c|c|}
\hline \multirow[t]{2}{*}{ Food group intakes (outcome measures) } & \multicolumn{3}{|c|}{$\log _{e}(\alpha$-tocopherol $)$} & \multicolumn{3}{|c|}{$\log _{e}(\gamma$-tocopherol $)$} & \multicolumn{3}{|c|}{$\gamma$-Tocopherol: $\alpha$-tocopherol } \\
\hline & Slope & $\mathrm{SE}$ & $P \neq$ & Slope & SE & $P \ddagger$ & Slope & SE & $P \ddagger$ \\
\hline \multicolumn{10}{|c|}{ 65-year-olds free living, male and female combined $(n 696)$} \\
\hline PUFA-rich margarines $(\mathrm{g} / 7 \mathrm{~d})$ & 5.92 & 0.93 & $<0.0001$ & -2.59 & 0.62 & $<0.0001$ & -65.4 & 8.7 & $<0.0001$ \\
\hline Non-PUFA-rich spreads $(\mathrm{g} / 7 \mathrm{~d}) \S$ & -0.54 & 0.95 & 0.6 & 3.84 & 0.61 & $<0.0001$ & 53.7 & 8.7 & $<0.0001$ \\
\hline Fresh fruit $(g / 7 d) \|$ & 4.39 & 1.79 & 0.01 & -1.23 & $1 \cdot 18$ & 0.3 & -39.2 & $16 \cdot 8$ & 0.02 \\
\hline Fruit juices and drinks $(\mathrm{g} / 7 \mathrm{~d})$ q & 2.51 & 1.40 & 0.07 & -1.33 & 0.92 & 0.1 & $-27 . \overline{5}$ & $13 \cdot 1$ & 0.04 \\
\hline Sugar $(g / 7 d)$ & -3.49 & 0.95 & 0.0002 & 0.25 & 0.62 & 0.7 & 23.2 & 8.9 & 0.009 \\
\hline \multicolumn{10}{|c|}{ 35-64-year-old, male and female combined $(n 624) \dagger$} \\
\hline PUFA-rich margarines $(\mathrm{g} / 7 \mathrm{~d})$ & 1.65 & 0.53 & 0.002 & -0.28 & 0.52 & 0.6 & $-26 \cdot 0$ & $7 \cdot 6$ & 0.0007 \\
\hline Non-PUFA-rich spreads $(\mathrm{g} / 7 \mathrm{~d}) \S$ & 0.085 & 0.9 & 0.9 & 0.81 & 0.60 & 0.2 & $10 \cdot 1$ & $8 \cdot 8$ & 0.2 \\
\hline Fresh fruit $(g / 7 d) \|$ & 1.37 & 1.97 & 0.5 & -2.53 & 1.93 & 0.2 & $-60 \cdot 4$ & 28.4 & 0.03 \\
\hline Fruit juices and drinks $(\mathrm{g} / 7 \mathrm{~d})$ q & $3 \cdot 18$ & 1.95 & 0.1 & -0.26 & 1.91 & $0 . \overline{9}$ & -56 & 28 & 0.05 \\
\hline Sugar $(g / 7 d)$ & -1.98 & 1.02 & 0.05 & -3.03 & 0.99 & 0.002 & $-14 \cdot 0$ & $14 \cdot 8$ & 0.3 \\
\hline \multicolumn{10}{|c|}{ 19-34-year-old, male and female combined $(n 290) \dagger$} \\
\hline PUFA-rich margarines $(\mathrm{g} / 7 \mathrm{~d})$ & 0.17 & 0.81 & 0.8 & -2.58 & 0.69 & 0.0002 & -44.5 & 11.0 & $<0.0001$ \\
\hline Non-PUFA-rich spreads $(\mathrm{g} / 7 \mathrm{~d}) \S$ & 0.18 & 0.93 & 0.8 & 0.95 & 0.81 & 0.2 & $10 \cdot 3$ & $13 \cdot 0$ & 0.4 \\
\hline Fresh fruit $(g / 7 d)$ & 1.99 & $2 \cdot 72$ & 0.5 & 3.56 & 2.37 & 0.1 & $42 \cdot 1$ & $38 \cdot 1$ & 0.3 \\
\hline Fruit juices and drinks $(\mathrm{g} / 7 \mathrm{~d})$ q & $5 \cdot 65$ & $2 \cdot 85$ & 0.05 & $1 \cdot 18$ & 2.51 & 0.6 & $-55 \cdot 3$ & $40 \cdot 1$ & 0.2 \\
\hline Sugar $(g / 7 d)$ & -4.47 & 1.41 & 0.002 & 1.02 & $1 \cdot 26$ & 0.4 & $73 \cdot 1$ & $19 \cdot 7$ & 0.0003 \\
\hline \multicolumn{10}{|c|}{ 4-18-year-old, male and female combined ( $n$ 842) } \\
\hline PUFA-rich margarines $(\mathrm{g} / 7 \mathrm{~d}) \S$ & 3.42 & 1.01 & 0.0007 & -1.28 & 0.42 & 0.002 & -23.5 & $5 \cdot 6$ & $<0.0001$ \\
\hline Non-PUFA-rich spreads $(\mathrm{g} / 7 \mathrm{~d}) \S$ & -1.92 & 1.00 & 0.06 & 0.07 & 0.42 & 0.9 & $6 \cdot 3$ & $5 \cdot 6$ & 0.3 \\
\hline Fresh fruit $(g / 7 d) \|$ & 6.55 & 2.85 & 0.02 & $-5 \cdot 13$ & $1 \cdot 18$ & $<0.0001$ & -81.5 & $15 \cdot 7$ & $<0.0001$ \\
\hline Fruit juices and drinks $(\mathrm{g} / 7 \mathrm{~d})$ q & 8.39 & 3.73 & 0.02 & -3.93 & 1.56 & 0.01 & $-69 \cdot 1$ & $20 \cdot 7$ & 0.0009 \\
\hline Sugar $(g / 7 d)$ & $-1 \cdot 36$ & 1.08 & 0.2 & 0.07 & 0.45 & 0.9 & 3.8 & $6 \cdot 1$ & 0.5 \\
\hline \multicolumn{10}{|c|}{ 1.5-4.5-year-old, male and female combined $(n 759)$} \\
\hline PUFA-rich margarines $(\mathrm{g} / 7 \mathrm{~d})$ & 1.70 & 0.49 & 0.0006 & -1.04 & 0.24 & $<0.0001$ & $-17 \cdot 2$ & 2.9 & $<0.0001$ \\
\hline Non-PUFA-rich spreads $(\mathrm{g} / 7 \mathrm{~d}) \S$ & -0.40 & 0.51 & 0.4 & 1.09 & 0.24 & $<0.0001$ & $16 \cdot 4$ & $3 \cdot 0$ & $<0.0001$ \\
\hline Fresh fruit $(g / 7 d) \|$ & 6.5 & 1.6 & $<0.0001$ & -0.71 & 0.79 & 0.4 & $-28 \cdot 3$ & $9 \cdot 8$ & 0.004 \\
\hline Fruit juices and drinks ( $g / 7 \mathrm{~d}$ ) & $5 \cdot 4$ & $2 \cdot 1$ & 0.01 & -1.94 & 1.02 & 0.06 & -41.4 & $12 \cdot 8$ & 0.001 \\
\hline Sugar $(g / 7 d)$ & $-2 \cdot 43$ & 0.89 & 0.006 & 0.48 & 0.43 & 0.3 & $8 \cdot 3$ & $5 \cdot 3$ & $0 \cdot 1$ \\
\hline
\end{tabular}

${ }^{*}$ For details of subjects and procedures, see p. 138.

$\dagger$ The 35-64- and 19-34-year-old age groups are subsets of the survey on 19-64-year-old adults.

$\ddagger P$ values for linear regression are adjusted for age, gender, and dietary energy and exclude vitamin $\mathrm{E}$ supplement-users. The food intake estimates were square-root-transformed in order to reduce the effect of skewed distributions.

$\S$ Non-PUFA spreads included all margarines and plant oil-derived spreads that are not listed as being rich in polyunsaturated fatty acids.

|| Fresh fruit included apples, pears, citrus, bananas, and soft fruit, but not canned fruit.

I Other soft drinks included all carbonated and non-carbonated soft drinks other than fruit juices and bottled water.

and gender group that was studied by White et al. 2001) and is also present but less strong in older men (Table 1). In middle-aged adults, the comparison between men and women yielded a different picture (Table 2). The picture in the middle-aged women closely resembled that for the older women (Table 1): their obesity indices were directly correlated with the $(\gamma$-tocopherol concentration and with the $\gamma$-tocopherol: $\alpha$-tocopherol concentration ratio. However, in the middle-aged men (Table 2), the obesity indices were directly correlated with both $\alpha$-tocopherol and with $\gamma$-tocopherol, but were not correlated with the $\gamma$-tocopherol: $\alpha$-tocopherol ratio. In the younger male and female adults (Table 3 ) some of the obesity indices were directly correlated with $\alpha$-tocopherol; a few were correlated with $\gamma$-tocopherol, but none were correlated with the $\gamma$-tocopherol: $\alpha$-tocopherol ratio, in men or women. In young people aged 4-18 years and in toddlers correlations between obesity indices and the vitamin $\mathrm{E}$ status indices were barely detected; however, fewer obesity indices were measured in these age groups. The possibility of a progressive development of these relationships throughout life, perhaps differing between men and women, seems worthy of further study, since it may help to predict obesity-related disease states, especially in older people.

The fact that in the present study two of the surveys provided fasting blood samples, whereas the other two did not, might have affected some of the relationships that we observed. However, we have no evidence that they did so, and indeed there was remarkable consistency between the surveys of adjacent age groups, despite the differences in fasting status.

Another recent study of US adults aged 40-50 years reported higher plasma $\gamma$-tocopherol, but unaltered $\alpha$-tocopherol concentrations, in smokers compared with non-smokers (Dietrich et al. 2003). In contrast, the present study on adults in the UK found lower plasma $\alpha$-tocopherol and either unaltered or lower plasma $\gamma$-tocopherol concentrations in smokers. An effect of smoking on vitamin $E$ status is relevant to the theory of reactive oxygen substances as a causative factor in the aetiology of smokingrelated illness. However, smokers did not appear to differ 
from non-smokers with respect to the observed relationships between the vitamin E status indices and the obesity indices studied here.

The NDNS relationships between vitamin E status indices and other plasma vitamin concentrations and also with nutrient intake patterns (Tables 5, 6, 7 and 8) confirm the observations of White et al. (2001) with one major exception. White et al. (2001) reported a strong inverse relationship between plasma $\alpha$ - and $\gamma$-tocopherols in postmenopausal women, whereas the present study recorded a direct correlation between these indices in all the age groups studied. This contrast may be partly a function of the difference in the extent of use of dietary supplements, especially vitamin $\mathrm{E}$, between the two populations, and the fact that in the present UK study, regular vitamin E-supplement users were deliberately excluded from the data analyses. In the US study, $>40 \%$ of the subjects were using supplements containing vitamin $\mathrm{E}$, whereas in the UK populations, before exclusion of the vitamin E supplement-users, only 3-20\%, varying with age group and timing of the survey, were using supplements that contained vitamin E.

In both the UK and the US studies, plasma $\alpha$-tocopherol was directly related to several fat-soluble and water-soluble vitamin status indices, and $\gamma$-tocopherol was inversely related to the same indices. In the UK study, in which different age groups were compared, this pattern was not confined to a single age and gender group, but was observed in all four surveys and all age groups. This was affected to only a minor degree by the inclusion or exclusion of those subjects who were taking vitamin E supplements.

The observed relationships with dietary choices in our present study (Tables 7, 8 and 9) suggest that those foods and nutrients which are considered 'healthy' and micronutrient-rich, as judged by their content of certain vitamins, minerals and fibre, tended to be directly related to plasma $\alpha$-tocopherol, inversely related to plasma $\gamma$-tocopherol and inversely related to $\gamma$-tocopherol: $\alpha$-tocopherol ratio. This was true for all age groups. Those nutrients such as sugar and MUFA, which are characteristic of 'less healthy' diets, also tended to be related to the vitamin E status indices, but in the opposite direction. Since MUFA were directly related to $\gamma$ tocopherol, we suggest that the MUFA index may act as a proxy for the choice of non-PUFA-rich, in preference to PUFA-rich, margarines and fat spreads.

Future work should include the separate estimation of dietary intakes of $\alpha$ - and $\gamma$-tocopherols in the NDNS further data analyses, based on $\alpha$ - and $\gamma$-tocopherol values in food tables. A major difficulty with this task arises from the commercial practice of using 'blended' oils and fats in commercially prepared foods, which contain plant oils from unidentified sources with varying amounts and ratios of the different forms of vitamin E. These may change over time and vary between brands. Nevertheless, the estimation of broad categories of intakes should be possible.

The metabolic differences between $\alpha$ and $\gamma$-tocopherols suggest that it may be over-simplistic to add them together and work just with the sum of the two forms of vitamin E. Previous studies (Handelman et al. 1985; Baker et al. 1986) have suggested that the $\gamma$-tocopherol: $\alpha$-tocopherol ratio has the characteristics of a useful index of $\alpha$-tocopherol intake. Our present observations suggest that it may, in some age-gender groups, also act as a risk indicator. An intervention study (Handelman et al. 1994) suggested that the within-subject variance in the $\gamma$-tocopherol: $\alpha$-tocopherol ratio in adipose tissue is relatively small. If the same is true for the corresponding plasma ratio, this could enhance its usefulness.

The relationships of the vitamin $\mathrm{E}$ indices cannot yet be satisfactorily explained in terms of physiological or biochemical mechanisms. It is possible that differences in fat accumulation and distribution between men and women might account for some of the observed gender-associated differences. Although a relatively high plasma $\gamma$-tocopherol level appears to be associated with increased risk (of obesity, especially in older women, of high-risk blood nutrient patterns, and of poor dietary choices), this does not necessarily imply that $\gamma$-tocopherol per se is an undesirable nutrient. Indeed several recent studies suggest that as a supplement or component of a balanced diet it may well be beneficial (Jiang et al. 2001; Gysin et al. 2002; Devaraj \& Traber, 2003). We suggest, however, that those metabolic or lifestyle differences between individuals that increase the plasma concentration of $\gamma$-tocopherol at the expense of that of $\alpha$-tocopherol may coincide with characteristics that are related to the risk of disease, especially in older women. If confirmed, the exploration of plasma $\alpha$ and $\gamma$-tocopherol concentrations may yield valuable predictive information. This could provide an opportunity for the development of new intermediate biochemical markers of intervention benefit, which may respond more rapidly or reproducibly during intervention than the longer-term and ultimate goals of disease prevention.

\section{Acknowledgements}

The NDNS series has been commissioned by the Department of Health and the Food Standards Agency (whose role was formerly assumed by the Ministry of Agriculture, Fisheries and Food). The surveys were performed by members of the Social Survey Division of the Office for National Statistics (ONS, formerly the Office for Population Censuses and Surveys, OPCS), or of the National Centre for Social Research (NCSR, formerly Social and Community Planning Research, SCPR), by members of MRC Human Nutrition Research (formerly the MRC Dunn Nutrition Unit) and by members of the Dental Schools of the Universities of Newcastle and Birmingham. We are indebted to the participants in the surveys for their cooperation and to our research colleagues and co-contractors for their assistance. The survey datasets were obtained from the University of Essex Data Archive or from the survey commissioners.

\section{References}

Ascherio A, Stampfer MJ, Colditz GA, Rimm E, Litin L \& Willett WC (1992) Correlations of vitamin A and E intakes with the plasma concentrations of carotenoids and tocopherols among American men and women. J Nutr 122, 1792-1801.

Baker H, Handelman GJ, Short S, Machlin LJ, Bhagavan HN, 
Dratz EA \& Frank O (1986) Comparison of plasma alpha and gamma tocopherol levels following chronic oral administration of either all-rac-alpha-tocopheryl acetate or RRR-alpha-tocopheryl acetate in normal adult male subjects. Am J Clin Nutr 43, 382-387.

Behrens WA \& Madere R (1986) Alpha- and gamma tocopherol concentrations in human serum. J Am Coll Nutr 5, 91-96.

Bieri JG \& Pouka Evart R (1974) Gamma tocopherol; metabolism, biological activity and significance in human vitamin E nutrition. Am J Clin Nutr 27, 980-986.

Blatt DH, Leonard SW \& Traber MG (2001) Vitamin E kinetics and the function of tocopherol regulatory proteins. Nutrition 17, 799-805.

Burton GW, Traber MG, Acuff RV, Walters DN, Kayden HJ, Hughes L \& Ingold KU (1998) Human plasma and tissue $\alpha$-tocopherol concentrations in response to supplementation with deuterated natural and synthetic vitamin E. Am J Clin Nutr 67, 669-684.

Cornwell DG, Williams MV, Wani AA, Wani G, Shen E \& Jones KH (2002) Mutagenicity of tocopherol quinones: evolutionary advantage of selective accumulation of dietary $\alpha$-tocopherol. Nutr Cancer 43, 111-118.

Devaraj S \& Traber MG (2003) $\gamma$-Tocopherol, the new vitamin E? Am J Clin Nutr 77, 530-531.

Dietrich M, Block G, Norkus EP, Hudes M, Traber MG, Cross CE \& Packer L (2003) Smoking and exposure to environmental tobacco smoke decrease some plasma antioxidants and increase $\gamma$-tocopherol in vivo after adjustment for dietary antioxidant intakes. Am J Clin Nutr 77, 160-166.

El-Sohemy A, Baylin A, Ascherio A, Kabagambe E, Spiegelman D \& Campos H (2001) Population-based study of $\alpha$ - and $\gamma$-tocopherol in plasma and adipose as biomarkers of intake in Costa Rican adults. Am J Clin Nutr 74, 356-363.

Finch S, Doyle W, Lowe C, Bates CJ, Prentice A, Smithers G \& Clarke P (1998) National Diet and Nutrition Survey: People Aged 65 Years or Over. Volume 1. Report of the Diet and Nutrition Survey. London: The Stationery Office.

Gregory J, Lowe S, Bates C, Prentice A, Jackson L, Smithers G, Wenlock R \& Farron M (2000) National Diet and Nutrition Survey: Young People Aged 4 to 18 Years. Volume 1: Report of the Diet and Nutrition Survey. London: The Stationery Office.

Gregory JR, Collins DL, Davies PSW, Hughes JM \& Clarke PC (1995) National Diet and Nutrition Survey: Children Aged 1.5 to 4.5 Years. Volume 1: Report of the Diet and Nutrition Survey. London: H. M. Stationery Office.

Gysin R, Azzi A \& Visarius T (2002) Gamma-tocopherol inhibits human cancer cell cycle progression and cell proliferation by down-regulation of cyclins. FASEB J 16, 1952-1954.

Han TS, Van Leer EM, Seidell JC \& Lean MEJ (1995) Waist circumference action levels of cariovascular risk factors: prevalence study in a random sample. Br Med J 311, 1401-1405.

Handelman GJ, Epstein WL, Peerson JM, Spiegelman D, Machlin LJ \& Dratz EA (1994) Human adipose $\alpha$-tocopherol and $\gamma$-tocopherol kinetics during and after $1 \mathrm{y}$ of $\alpha$-tocopherol supplementation. Am J Clin Nutr 59, 1025-1032.

Handelman GJ, Machlin LJ, Fitch K, Weiter JJ \& Dratz EA (1985) Oral $\alpha$-tocopherol supplements decrease plasma $\gamma$-tocopherol levels in humans. J Nutr 115, 807-813.

Henderson L, Gregory J, Irving K \& Swan G (2003a) The National Diet and Nutrition Survey: Adults Aged 19-64 Years. Volume 2: Energy, Protein, Carbohydrate, Fat and Alcohol Intake, London: The Stationery Office.

Henderson L, Irving K, Gregory J, Bates CJ, Prentice A, Swan G \& Farron M (2003b) The National Diet and Nutrition Survey:
Adults Aged 19-64 Years. Volume 3: Vitamin and Mineral Intake and Urinary Analyses, London: The Stationery Office.

Jiang Q, Christen S, Shigenaga MK \& Ames BN (2001) $\gamma$-Tocopherol, the major form of vitamin $\mathrm{E}$ in the US diet, deserves more attention. Am J Clin Nutr 74, 714-722.

Kontush A, Spranger T, Reich A, Baum K \& Beisiegel U (1999) Lipophilic antioxidants in blood plasma as markers of atherosclerosis: the role of alpha-carotene and gamma-tocopherol. Atherosclerosis 144, 117-122.

Lemcke-Norojarvi M, Kamal-Eldin A, Appelqvist L-A, Dimberg LH, Ohrvall M \& Vessby B (2001) Corn and sesame oils increase serum $\gamma$-tocopherol concentrations. J Nutr 131, 1195-1201.

McLaughlin PJ \& Weihrauch JL (1979) Vitamin E content of foods. J Am Diet Assoc 75, 647-665.

Morinobu T, Yoshikawa S, Hamamura K \& Tamai H (2003) Measurement of vitamin E metabolites by high-performance liquid chromatography during high-dose administration of $\alpha$-tocopherol. Eur J Clin Nutr 57, 410-414.

Ohrvall M, Sundlov G \& Vessby B (1996) Gamma, but not alpha, tocopherol levels in serum are reduced in coronary heart disease patients. J Intern Med 239, 111-117.

Rock CL, Jahnke MG, Gorenflo DW, Swartz M \& Messana JM (1997) Racial group differences in plasma concentrations of antioxidant vitamins and carotenoids in hemodialysis patients. Am J Clin Nutr 65, 844-850.

Ruston D, Hoare J, Henderson L, Gregory J, Bates CJ, Prentice A, Perks J, Swan G \& Farron M (2004) The National Diet and Nutrition Survey: Adults Aged 19-64 Years. Vol. 4: Nutritional status (anthropometry and blood analytes), blood pressure and physical activity. London: The Stationery Office.

Sinha R, Patterson BH, Mangels AR, Levander OA, Gibson T, Taylor PR \& Block G (1993) Determinants of plasma vitamin $\mathrm{E}$ in healthy males. Cancer Epidemiol Biomarkers Prev 2 , 473-479.

Sontag TJ \& Parker RS (2002) Cytochrome P450 $\omega$-hydroxylase pathway of tocopherol catabolism. J Biol Chem 277, 25290-25296.

Swanson JE, Ben RN, Burton GW \& Parker RS (1999) Urinary excretion of 2,7,8-trimethyl-2-( $\beta$-carboxyethyl)-6-hydroxychroman is a major route of elimination of $\gamma$-tocopherol in humans. J Lipid Res 40, 665-671.

Thurnham DI, Smith E \& Flora PS (1988) Concurrent liquid chromatographic assay of retinol, $\alpha$-tocopherol, $\beta$-carotene, $\alpha$-carotene, lycopene and $\beta$-cryptoxanthin in plasma, with tocopherol acetate as internal standard. Clin Chem 34, 337-381.

Traber MG \& Kayden HJ (1989) Preferential incorporation of $\alpha$ tocopherol vs $\gamma$-tocopherol in human lipoproteins. Am J Clin Nutr 49, 517-526.

Vatassery GT, Johnson GJ \& Krezowski AM (1983) Changes in vitamin $\mathrm{E}$ concentrations in human plasma and platelets with age. J Am Coll Nutr 2, 369-375.

Vogel S, Contois JH, Tucker KL, Wilson PW, Schaefer EJ \& Lammi-Keefe CJ (1997) Plasma retinol and plasma lipoprotein tocopherol and carotenoid concentrations in healthy elderly participants of the Framingham Heart Study. Am J Clin Nutr 66, 950-958.

Wechter WJ, Kantoci D, Murray ED, D’Amico DC, Jung ME \& Wang W-H (1996) A new endogenous natriuretic factor: LLUalpha. Proc Natl Acad Sci USA 93, 6002-6007.

White E, Kristal AR, Shikany JM, Wilson AC, Chen C, MaresPerlman JA, Masaki KH \& Caan BJ (2001) Correlates of serum $\alpha$ and $\gamma$-tocopherol in the Women's Health Initiative. Ann Epidemiol 11, 136-144. 